\title{
Interprofessional education development: not for the faint of heart
}

This article was published in the following Dove Press journal:

Advances in Medical Education and Practice

18 May 2017

Number of times this article has been viewed

\author{
Deborah B Fahs' \\ Linda Honan' \\ Rosana Gonzalez-Colaso ${ }^{2}$ \\ Eve R Colson ${ }^{3}$ \\ 'Division of Acute Care/Health \\ Systems, Yale School of Nursing, \\ West Haven, ${ }^{2}$ Department of Internal \\ Medicine, Physician Associate \\ Program, ${ }^{3}$ Department of Pediatrics, \\ Yale School of Medicine, New Haven, \\ CT, USA
}

\begin{abstract}
Interprofessional education (IPE) has the potential to improve communication, collaboration and coordination of care, leading to improved health care outcomes. Promoting IPE has become an aim for many professional schools. However, there are challenges to implementing meaningful curricula that involve multiple health care professional schools. In this study, we outline 12 lessons learned when designing and implementing an Interprofessional Longitudinal Clinical Experience (ILCE) for 247 students from a School of Nursing, Medicine and Physician Associate Program in New England. Lessons learned over 4 years include pilot, evaluate and refine projects; create a formal interprofessional organizational structure; involve faculty who are passionate ambassadors for IPE; procure and maintain financial support; recognize power struggles and bias; overcome logistical conundrums to realize common goals, secure clinical sites and prepare IPE coaches; expect there will always be another hurdle; do not go it alone; recruit experts; recognize role differentiation and similarities; be aware of fragility of students and faculty and collect data to assess, evaluate, improve and gain buy-in. We were able to successfully implement a large program for students from three different health care professional schools that takes place in the clinical setting with faculty coaches, patients and their families. We hope that the lessons learned can be instructive to those considering a similar effort.
\end{abstract}

Keywords: professional education, intersectional collaboration, curriculum, teamwork, interdisciplinary communication

\section{Introduction}

Reducing medical errors and improving patient outcomes are goals gaining momentum in the United States and globally. ${ }^{1}$ Over a decade ago, the Institute of Medicine (IOM) suggested improving collaboration and coordination among health care providers as one possible solution to providing consistent, high-quality care. ${ }^{2-4}$ However, without joint training, health care providers cannot learn to collaborate and coordinate care.

Several organizations that oversee the accreditation of programs in health care now require that students train together. For example, the Liaison Committee on Medical Education requires that medical schools prepare students for interprofessional collaboration, and the Accreditation Review Commission on Education for the Physician Assistant, Inc. holds similar requirements. ${ }^{5,6}$ While interprofessional coursework is not currently required by schools of nursing, it is recommended by the American Association of Colleges of Nursing (AACN) and the Commission on Collegiate Nursing Education (CCNE) as a means to improving quality of care. ${ }^{7,8}$

In addition, six organizations, including the AACN and the Association of American Medical Colleges (AAMC), joined together to develop core competencies for
Correspondence: Deborah B Fahs Division of Acute Care/Health Systems, Yale School of Nursing, PO Box 27399, West Haven, CT 06516, USA

$\mathrm{Tel}+\mathrm{I} 2032131224$

Fax+l 2037374480

Email deborah.fahs@yale.edu 
interprofessional collaborative practice in 2011.9 A 2016 update of these competencies is endorsed by 15 health professional organizations, including the Physician Assistant Education Association (PAEA).$^{10}$ These competencies include the understanding of values and ethics for interprofessional practice, understanding each other's roles and responsibilities for collaborative practice, improving interprofessional communication and being able to participate effectively in interprofessional teams.

However, interprofessional teamwork does not always occur naturally or effortlessly, and it is problematic that health professional students graduate from their respective programs of study never having shared formal learning experiences in the classroom or clinical setting. Nevertheless, there is an expectation that upon graduation, they will transition smoothly and seamlessly as effective interprofessional team members. ${ }^{11,12}$ Indeed, new graduates' initial impressions about the prospects of interprofessional teamwork have been illustrated among a cohort of internal medicine residents who reported difficulty in understanding nurse practitioners' roles and responsibilities, as well as nurse practitioner trainees who questioned their ability to work alongside physicians during an interprofessional education (IPE) intervention. ${ }^{13}$

Even though common coursework among the health professional schools exists, most students continue to be educated in silos. ${ }^{14}$ Although some health professional programs do offer IPE, most activities are limited to the classroom, laboratory and/or simulation venues rather than taking place in the clinical setting. ${ }^{15,16}$ The challenge of these approaches is to provide pre-licensure students with meaningful interprofessional learning activities that can be internalized once they face the complexities and variability of real clinical experiences.

While IPE programs in institutions of higher learning are becoming increasingly common, initiating, implementing, evaluating and sustaining meaningful experiential learning in large programs of study are challenging. Curricular planning must be carefully thought out, involving faculty representation from different professions and disciplines. Using an iterative, evaluative approach, our group's intention was to create interprofessional experiences in clinical sites when interacting with real patients. Our IPE goals for our students are to observe, experience and reflect on effective interprofessional team dynamics; learn to resolve interprofessional group conflict if it arises; foster a leveling of professional hierarchies and understand and respect one another's professional roles and scopes of practice through a longitudinal approach to IPE. We aim to create a culture that recognizes the valuable effects of IPE in the preparation of future leaders who will practice, research and teach collaboratively.

Our innovation is the Interprofessional Longitudinal Clinical Experience (ILCE) where first-year graduate entry prespecialty in nursing (GEPN), medical and physician associate (PA) students learn together in the classroom, laboratory, simulation and in consistent clinical settings with patients for a period of 8 months. Of note, our GEPN program is an accelerated three-year program in which students enter with a minimum of a Bachelor of Arts or Science degree; complete their registered nurse ( $\mathrm{RN}$ ) curriculum during the first year and then specialize in their area of advanced practice nursing (family practice, pediatrics, acute care, psychiatricmental health, midwifery-women's health or adult-geriatrics) during the remaining two years of study. Our medical students are educated in a four-year integrated program, and our PA curriculum expands over 27 months.

Assuredly, designing interprofessional curricula is no easy task and there are no simple formulas. This study offers insights gained as we have designed an innovative approach to interprofessional learning, with the main focus on experiential interprofessional clinical practice. Our experience may offer guidance to educators undertaking this immense commitment toward the aim of improving future interprofessional care and subsequent patient health outcomes. We therefore offer the reader 12 identified lessons learned over four years of experience.

\section{Identified lessons learned from instituting IPE Identified lesson I: pilot, evaluate and refine projects}

Prior to integrating the ILCE coursework in each program's curriculum, we conducted three pilot curricula over three academic years to assess, evaluate and refine the final product. Our successful pilot work included 184 students from the medical, GEPN and PA programs who elected to participate.

The three years of pilots were critical to our success and should be considered indispensable when developing IPE. In retrospect, year one was about proving parity, developing trust with colleagues and curriculum development. Our pilot one curriculum focused on communication, history taking and physical examination. We began with one clinician from each of the three professional graduate schools, who performed shared history taking and physical examinations. Our patients were selected by hospital staff and had consented and were unknown to the clinicians. These activities were observed by 
a group of faculty representing each school. It was clear that history taking and physical examination skills are the same in all three programs of study. As one faculty member said, "A heart murmur is a heart murmur". While we all believed this, it was necessary to prove it by role modeling what it is each profession does to the "others". Once parity was determined, we could move on to curriculum development.

During pilot one, other important discussions emerged around having shared language and signs and symbols commensurate with participants' professional identities. For example, discussions occurred over wearing a white coat with the use of scrubs versus business clothing; wearing a short lab coat versus a long lab coat and how these choices might influence patients' role recognition while clinicians are undertaking similar responsibilities. Thus, beyond traditional curriculum development, issues of resources, scheduling and timing, additional "real-world" problems presented themselves in piloting and offered educators an opportunity to thoughtfully consider responses.

Students were active members of the ILCE team and assisted in refining and developing the content used for pilot two. In this pilot, beyond scaling up our number of students participating and increasing the length of the program from one semester to one year, the curriculum was augmented by adding content on cultural sensitivity and quality improvement. But year two was also a time of data mining. We continued to seek student and coach feedback, and after considering opinions, criticism and strengths, pilot three was initiated.

In the third year, we dealt with outside influences and, in many cases, opposition. We refined the curriculum to this end, also recognizing when we needed to scale back. We were overly ambitious by including too many aims and activities, including quality improvement projects and cultural diversity content that caused disagreement and angst among faculty and students. Be prepared to trim some of the objectives of your curriculum, if necessary.

Pilots were critical in helping faculty to create, enact and evaluate our curriculum's effectiveness and aims and also to develop as a team. They also gave us the necessary time to develop strategies to deal with opposing influences to IPE.

\section{Identified lesson 2: create a formal interprofessional organizational structure to develop common goals}

Because the sheer number of students when combining three programs was so overwhelming, a more manageable approach was necessary; thus, we created a new organizational structure. We selected one of our physician colleagues to direct the program followed by three associate directors, one from each professional school. We agreed all positions would rotate among the three schools after a few years, including the role as director of the program. One associate from our PA program was responsible for designing the interprofessional teamwork curriculum in consultation with an organizational psychologist; one from the GEPN program was responsible for adapting the clinical skills curriculum to our IPE context (history taking and physical examination and communication) and the third, from medicine, was tasked with leading the development and retention of clinical sites and coaches. Reporting to the associate directors were ten IPE section leaders representing each of the three programs, who were each responsible for six to seven interprofessional teams. There were four students to each team, for a total of 24-28 students per section.

It is paramount to create a leadership structure with equal faculty representation from all schools who share responsibility in final decision making. Each faculty member must "own" his or her area of responsibility and accept any criticism that may arise to achieve common goals. It is also important for students and clinical coaches to serve on curricular advisory committees for their own and the other schools. Finally, additional structures that should be considered are shared faculty appointments.

\section{Identified lesson 3: involve faculty who are passionate ambassadors for IPE}

For IPE to be successful, faculty must be committed and confident in both their teaching and clinical abilities. In our case, a "bottom-up" approach to create change in all three schools occurred. Passionate faculty from each school met, worked diligently, continually evaluated our pilots and garnered the data necessary to keep moving toward the day that ILCE was formalized in all three schools. Armed with data, we were able to gain support from senior leadership in our university. Thus, for us, a bottom-up approach was crucial to the development and operationalization of IPE. It allowed us to learn about, from and with each other.

IPE endeavors are not for the "faint of heart"; faculty must realize that they are continually being observed and will be viewed as speaking for his or her profession. Additionally, since most faculty are already overburdened with teaching, clinical, scholarship and committee responsibilities, passionate advocates willing to put the work in initially, on top of their assigned duties, are essential. Faculty need to anticipate weekly faculty meetings, coach encounters, clinical site visits, lectures, laboratory work and simulation 
activities. But they must also be prepared to set aside time for "spreading the word" through interprofessional presentations and publications.

\section{Identified lesson 4: Procure and maintain financial support}

The creation of a realistic budget and a detailed business plan is essential to success. Fortunately, our lead physician colleague obtained support from the Josiah Macy Jr. Foundation and from the Doctor's Company Foundation to support our IPE efforts initially. While the grants provided considerable financial resources for developing and piloting our IPE endeavors, we were fully cognizant that we needed our administrators' and deans' support to ensure the future existence of IPE. Additionally, we chose not to designate funds for faculty support in our grants but used funds for initial administrative support, consultants and research activities. This was a deliberate choice, as had we built faculty support into the grant; once the grant was gone, the program would be threatened.

Thus, a business model must be developed, marketed and sold to all stakeholders. Once the program is developed, it is necessary to receive credit and recognition for the increased workload. It is also important to realize that the time involved in planning and evaluating curricula should be included in your budget. Financial sharing of resources should also be considered and shared in financial planning. This can include the simulation center, physical assessment laboratory and classroom spaces, as well as researchers, grant writers and site coordinators. Our ILCE faculty presented our successful assessment findings from the first three IPE pilots, and fortunately, our efforts were met with enthusiasm and support from our deans.

\section{Identified lesson 5: recognize power struggles and bias}

Undertaking IPE will quickly morph beyond curricula into power dynamics and issues of conflict, so it is important to consider these matters as foreground when developing IPE. Dissent must be anticipated and you must be prepared to prove your profession's capacity to others who may question your level of competency. A "thick skin" is required, as well as a reflective nature. "Old professional feuds" may emerge, and it is important to think critically about the inevitable conflicts that will arise. Professional boundaries can bring up power issues and hierarchies, and professional stereotyping will be encountered. Students' reluctance or even resistance to learn from "other" faculty may be seen. Tribal behaviors among some students from the various interprofessional programs may surface, and it is the faculty's responsibility to dispel antiquated status differentials in an attempt to create equitable team members.

Support and mentoring must be provided to the clinical coaches as well, since stereotyping and power disparities may be reinforced by faculty, clinical coaches and clinicians. Anticipate that power issues will surface in subtle ways. Examples include letterhead communication disseminated to the community without acknowledging the graduate school of nursing or expressions that the "doctor" writes the medical orders rather than the "clinician" or the "health care provider". Role bias can also be seen in duties assigned to different students, such as clinical coaches asking the GEPN students to inspect the supply closet, while the PA and medical students participated in medical rounding. Our faculty ILCE team addressed these issues, respectively, by creating our own ILCE letterhead inclusive of all three programs, using a direct approach as reinforcement to all clinicians and faculty that Advanced Practice Registered Nurses (APRNs) and PAs write patient orders, and by counseling clinical coaches that students must be treated equitably.

As with our IPE students, working in faculty teams from "other" health care programs was something we had never before experienced, and at times, other faculty were regarded with suspicion and doubt. But by pilot year two, we inadvertently noticed that we no longer sat with faculty from our like programs and instead, blended together. On occasion, particular team members received, what we considered, undeserved criticism by an outside force, and the support our team lent to those faculty members was palpable. This was an epiphany for the IPE faculty as we realized that we were successfully bonding as a cohesive faculty team committed to two common goals: improving our students' education and future clinical practice and ensuring our patients' well-being and safety. Becoming an interprofessional team takes time but is worthy of all your investments.

\section{Identified lesson 6: overcome logistical conundrums to realize common goals}

Infrastructures posed some of the greatest barriers to designing and implementing interprofessional curricula. The devil is in the details; therefore, be realistic. Create the curriculum in small increments and do not take on too much at once. Programs of study have varying vacation times, academic calendars and course schedules; therefore, all schools must be willing to find common ground. Since all three of our programs include a physical examination 
course, we worked together to synchronize timing and provide consistency in course content. Timing can make all the difference. We introduced the course not only in the student's first year of study but also within the first few weeks of their arrival to school. Although there were preexisting stereotypes about one another's profession, we hoped to break them down before they became fixed and perpetuated. Additionally, since all students had the same level of competency, competition was less of an issue. One problematic area during pilot testing was course credit, as the medical students received credit, while the GEPN and PA students did not. This inconsistency resulted in attrition and conflict among the three programs of study. Other considerations include space issues, specifically, finding a lecture hall large enough to accommodate 247 students, and transportation challenges, as the GEPN program is located on a separate campus.

\section{Identified lesson 7: secure clinical sites and prepare IPE coaches}

Finding clinical sites proved to be arduous and time-consuming. We had to establish new community relationships in placing three to four students at each clinical site, being careful not to disrupt existing student clinical sites within our own programs. We were also hindered when local universities paid clinical coaches and clinical site administrators who had "no conflict" contracts. Although finding clinical coaches was difficult, mentoring them to feel comfortable in teaching different cohorts of students posed additional struggles. To lessen the time burden on coaches, we tried enlisting multiple coaches at each site to share the teaching load each week. This resulted in a lack of consistency, however, and negatively impacted student feedback, since some coaches were not familiar with the students. We therefore decided that there would be no more than three clinical coaches sharing the teaching per clinical site.

Finding sites close to the university was also difficult, and the varying clinical site experiences (hospitals, dialysis units, emergency departments, rehabilitation centers, hospice centers, outpatient inflammatory bowel clinics, cystic fibrosis centers, etc.) also produced conflict among students. "They are learning more at their site than we are", was a common complaint. Students should be told at the outset that they need to be self-directed and flexible learners.

In pilot year two, we placed six students per site and learned that this was burdensome to coaches and negatively impacted students' overall learning experience. We decided that a student "pod" should consist of no more than four students. We also learned that our clinical coaches became frustrated when students from different programs were learning history and physical examination content at varying times, thus making it difficult for coaches to maintain consistency. We worked diligently to align our history and physical examination content among the three programs to lessen this additional burden on our coaches and taught strategies including allowing learners to teach their peers.

We had to agree on a systematic means of contacting our coaches whether via email, telephone or in-person, by attending some of the clinical sessions. Every effort was made to keep in close contact with our coaches to help resolve clinical problems and ask for feedback. But we also needed to be cognizant of the fine line that exists between extending complete autonomy to the student coaches and their interpretation of "over-communication". Workshops were provided with continuing medical education units to assist coaches in navigating "uncharted territory". Because coaches volunteered their time to mentor our student teams while working in busy and stressful in- and outpatient settings, every effort was made to repeatedly thank them for their valuable clinical expertise and time. Despite all our best efforts, we were faced with coach attrition and finding replacements mid-year, which proved difficult but doable because of our committed ILCE faculty.

\section{Identified lesson 8: expect there will always be another hurdle}

While all health professions' national leadership, societies and accrediting agencies support IPE, local state board regulations may have not kept pace with the national standard, and this may pose legal challenges to IPE. While boards of nursing encourage and even mandate IPE, antiquated policies may remain in place and should be investigated early. To illustrate, it would not be unusual that registered nursing regulations require only RNs may mentor their own students. These restrictions pose major barriers to establishing the very educational endeavors they claim to support. The irony is that neither the first-year medical nor PA students are under the same restrictions.

Grant restrictions can also be problematic. There are graduate-level IPE grants limited to licensed RNs and do not include accelerated master's entry programs such as ours. Since none of our students (medicine, GEPN or PA) hold licenses to practice, it is puzzling as to why funding is not inclusive to all graduate-level nursing students. Unfortunately, in some instances, our hands remain tied as we continue to question, "Why the bias?" If we expect students 
to be on par with one another, these incongruences must be brought to the forefront, examined and rectified.

\section{Identified lesson 9: do not go at it alone: recruit experts}

We developed our framework around interprofessional teamwork, recognizing that a seasoned clinician and educator cannot guarantee a skillset that includes interprofessional conflict resolution, intergroup dynamics and team development process. We therefore enlisted the aid of an organizational psychologist to guide our efforts. Through our pilot projects, we learned that students from all three programs enthusiastically embraced simulation activities, citing its importance related to team building and reinforcing their history and physical examination skills toward establishing a differential diagnosis. Therefore, we recruited the school of nursing simulation director who had expertise in simulation experiences. We also recruited the clinical coordinator from the school of nursing, to administrate and manage clinical sites, and administrative assistants from the PA and medical school, to assist in organizing our program. And we called on all three schools' educational experts in evaluation and assessment. It is important to find experts across a diverse skill set and recruit them into your IPE efforts.

\section{Identified lesson 10: recognize role differentiation and similarities}

Interprofessional endeavors must always focus on the patient and, with that, ensure that each clinician's training and scope of practice are clearly defined. We found that students were unfamiliar with one another's future professional roles, particularly between PAs and APRNs. We remedied this by inviting a panel of seasoned physicians, PAs and APRNs in a large group venue to explain their education and scopes of practice. Students were given the opportunity to comment and ask questions, and it was clear that their own clinical experiences were most valuable to their understanding of one another's professional roles. ${ }^{17}$ Our goal was not meant to remove differences or blur roles of the various health care providers but to recognize the importance of each provider's contributions and strengths. Students learned that roles and responsibilities are often context dependent and may be related to federal or state regulations, professional license or certification regulations. It was also crucial for students to recognize that while their opinions may differ, they must work together as functional teams to problem solve with the end goal of ensuring best patient outcomes.

\section{Identified lesson II: be aware of the fragility of students and faculty}

Faculty must recognize that novice health professional students are fearful of hurting patients, being unprepared and feeling "lesser" despite the individual program of study. This is exacerbated in IPE because intergroup differences in clinical knowledge and skills may be intrinsic to each program's admission criteria. Faculty must create an environment that allows for and welcomes vulnerability, as this is a critical part of interprofessional team building. Inevitably, competition among interprofessional students will arise; therefore, students must be encouraged to teach and support one another. It has been encouraging to witness the cohesive bonds established in some of the student teams and the close friendships that developed as they began socializing outside of the clinical setting. Some interprofessional student cohorts formed lasting friendships throughout the remainder of their programs, even though they were no longer involved in their IPE coursework. Additionally, after three years of pilot testing, there is spillover affecting our school's culture, with expansion of student-initiated interprofessional elective and interest groups that are open to all.

It is important to recognize that faculty members will, at times, feel fragile, frustrated and overwhelmed. Burnout occurred with almost every faculty member but, fortunately for us, at varying times within the curriculum development phase. Our IPE faculty formed strong and unified bonds with one another, and even though differences of opinion emerged, we were able to provide support, encouragement and extend a sense of optimism to those faculty who felt particularly downtrodden. During those times, it was particularly important that we looked toward the positive impact IPE would have in the long term, so that burnout would not become pervasive.

\section{Identified lesson 12: collect data to assess, evaluate, improve and gain buy-in}

Data are paramount to moving interprofessional endeavors forward. One needs to move beyond requirements of regulations and decide on the how, what and why of IPE. What is the program's aim and, in the end, does it make a difference? Keep in mind that common interprofessional goals and objectives must be well defined and that matching course content with objectives is crucial to successfully implementing IPE curricula. We asked for continual feedback from both clinical coaches and students and used it to improve and refine our course content. 
We cast the net wide and surveyed students with a variety of quantitative and qualitative tools including readiness for interprofessional learning scales, attitudes toward interprofessional learning, empathy and teamwork measurements. ${ }^{17-21}$ To assess whether our pilot was effective in teaching students interprofessionalism, we created simulations for ILCE participants, comparing their actions to non-participants. The sessions were videotaped and evaluated by clinicians not affiliated with ILCE. Interestingly, while there was parity in students' ability to perform history taking, physical examination and clinical reasoning when matched against students who did not participate in ILCE, there was a statistically significant difference in their ILCE teamwork skills ( $p=0.0001)$, with ILCE students performing better than their matched peers. ${ }^{20,21}$ We measured students' empathy toward patients in addition to their ability to perform in teams and found that students in the interprofessional groups demonstrated greater empathy toward their patients and worked more effectively as team members than those in control groups. ${ }^{20,21}$ We presented these data to our administrators and deans to validate that our IPE endeavors were advantageous and even critical to education, and thus, that it was worth supporting faculty efforts and institutional budgeting.

It is also critical to measure the long-term and logistical impact of IPE. In other words, how do we ascertain that didactic and clinical content, which covers interprofessional teamwork, role awareness, communication and leveling power differentials, really translates into student's future practice? Challenges to measuring the effect of interprofessional teamwork in our ILCE cohort longitudinally are compounded because of differing end points in our program (27 months for PAs, 3 years for GEPNs and 4 years for medicine). Student feedback and careful evaluation processes were continual and key to improving and refining our interprofessional curricula. Assessment and evaluation should be ongoing, and you must be prepared to make mistakes, recommit and redo. Bottom line: you must plan, plan and plan. It is a long and never-ending process that requires fluidity and flexibility on the part of IPE faculty.

\section{Conclusion}

Developing and implementing IPE requires a tremendous commitment on the part of faculty, and there are a multitude of impediments including a lack of financial support, dispelling role bias and stereotyping, organizational and logistical challenges, securing clinical sites and training coaches, recognizing the vulnerability of students as they fear working in teams outside of their own profession, faculty burnout and best method evaluation tools. Faculty must be prepared to bring forth their time, creativity, flexibility, fortitude, will, courage and passion to ensure success. It will be a never-ending process and is not for the faint of heart. But dedicated faculty who choose to invest in the long-term educational success of students may subsequently affect more positive patient outcomes. What we can say for certain is that you will enjoy inordinate professional satisfaction, develop supportive colleagues and gain meaningful personal reward.

\section{Acknowledgment}

This work was funded in part by the Doctor's Company Foundation and the Josiah Macy Jr. Foundation.

\section{Disclosure}

The authors report no conflicts of interest in this work.

\section{References}

1. Horsburgh M, Perkins R, Coyle B, Degeling P. The professional subcultures of students entering medicine, nursing and pharmacy programmes. J Interprof Care. 2006;20(4):425-431.

2. Koh LT, Corrigan TM, Donaldson MS (Eds). To Err Is Human: Building a Safer Health System. Washington D.C. National Academy of Sciences; 1999. Available from www.csen.com/err.pdf. Accessed December 19, 1999.

3. Institute of Medicine. Crossing the Quality Chasm: A New Health System for the $21^{\text {st }}$ Century. Washington, DC: National Academy of Sciences; 2001. Available from: https://www.nap.edu/html/quality_chasm/ reportbrief/pdf. Accessed December 19, 2016.

4. Institute of Medicine. Health Professions Education: A Bridge to Quality. Washington, DC: National Academy of Sciences; 2003. Available from: https.//www.ncbi.nlm.nih.gov/books/NBK221528/pdf/Bookshelf_NBK221528.pdf. Accessed December 19, 2016.

5. Liaison Committee on Medical Education. Functions and Structure of a Medical School: Standards for Accreditation of Medical Education Programs Leading to the M.D. Degree. Washington, DC: Liaison Committee on Medical Education; 2013.

6. Accreditation Review Commission on Education for the Physician Assistant, Inc. Accreditation Standards for Physician Assistant Education. 4th ed. Johns Creek, GA: ARC-PA; 2010.

7. American Association of Colleges of Nursing. The Essentials of Master's Education in Nursing. Washington, DC: AACN; 2011.

8. Commission on Collegiate Nursing Education. Standards for Accreditation of Baccalaureate and Graduate Nursing Programs. Washington, DC: CCNE; 2013.

9. Interprofessional Education Collaborative Expert Panel. Core Competencies for Interprofessional Collaborative Practice: Report of an Expert Panel. Washington, DC: Interprofessional Education Collaborative; 2011.

10. Interprofessional Education Collaborative. Core Competencies for Interprofessional Collaborative Practice: 2016 Update. Washington, DC: Interprofessional Education Collaborative; 2016.

11. Reeves S, Zwarenstein M, Goldman J, et al. Interprofessional education: effects on professional practice and health care outcomes. Cochrane Database Syst Rev. 2008;(1):CD002213. 
12. Margalit R, Thompson S, Visovsky C, et al. From professional silos to interprofessional education: campus wide focus on quality of care. Qual Manag Health Care. 2009;18(3):165-173.

13. Meyer EM, Zapatka S, Vrienza RS. The development of professional identity and the formation of teams in the veterans affairs Connecticut Healthcare System's Center of Excellence in Primary Care Education program (CoEPCE). Acad Med. 2015;90(6):802-809.

14. Barnsteiner JH, Disch JM, Hall L, Mayer D, Moore SM. Promoting interprofessional education. Nurs Outlook. 2007;55(3):144-150.

15. Acquavita SP, Lewis MA, Aparicio E, Pecukonis E. Student perspectives on interprofessional education and experiences. J Allied Health. 2014;43(2):31-36.

16. Weatherly JA. Student Perspectives on Interprofessional Education: Implications for Curriculum Development [thesis]. New Haven: Yale University; 2016.
17. Honan L, Fahs DB, Talwalkar JS, Kayingo G. Interprofessional learning: perceptions of first year health students. J Nurs Educ Pract. 2015; 5(6):39-49.

18. Talwalkar JS, Fahs DB, Kayingo G, Wong R, Jeon S, Honan L. Readiness for interprofessional learning among healthcare professional students. Int J Med Educ. 2016;7:144-148.

19. Wong R, Fahs DB, Talwalkar J, et al. A longitudinal study of health professional students' attitudes toward interprofessional education at an American University. J Interprof Care. 2016;30(2):191-200.

20. Colson E, Addy T, Brissette D, et al. An interprofessional longitudinal experience for $1^{\text {st }}$-year students: results of pilot 2. Poster presentation at: Medical Education Day; June 2016; New Haven, CT.

21. Colson E, Kennedy D, Brissette D, et al. Assessing teamwork in interprofessional clinical education. In: Ottawa Conference on Medical Education Evaluation; March 19-23, 2016; Perth, Australia. Abstract.

\section{Publish your work in this journal}

Advances in Medical Education and Practice is an international, peerreviewed, open access journal that aims to present and publish research on Medical Education covering medical, dental, nursing and allied health care professional education. The journal covers undergraduate education, postgraduate training and continuing medical education

\section{Dovepress}

including emerging trends and innovative models linking education, research, and health care services. The manuscript management system is completely online and includes a very quick and fair peer-review system. Visit http://www.dovepress.com/testimonials.php to read real quotes from published authors.

Submit your manuscript here: http://www.dovepress.com/advances-in-medical-education-and-practice-journal 